\title{
Wind Turbine Wakes in Directionally Varying Wind Shears
}

\author{
Abkar, Mahdi; Porté-Agel, Fernando; Sørensen, Jens
}

Published in:

Progress in Turbulence VIII

Link to article, DOI:

10.1007/978-3-030-22196-6_49

Publication date:

2019

Document Version

Peer reviewed version

Link back to DTU Orbit

Citation $(A P A)$ :

Abkar, M., Porté-Agel, F., \& Sørensen, J. (2019). Wind Turbine Wakes in Directionally Varying Wind Shears. In Progress in Turbulence VIII : iTi 2018 (Vol. 226, pp. 311-316). Springer. Springer Proceedings in Physics Vol. 226 https://doi.org/10.1007/978-3-030-22196-6_49

\section{General rights}

Copyright and moral rights for the publications made accessible in the public portal are retained by the authors and/or other copyright owners and it is a condition of accessing publications that users recognise and abide by the legal requirements associated with these rights.

- Users may download and print one copy of any publication from the public portal for the purpose of private study or research.

- You may not further distribute the material or use it for any profit-making activity or commercial gain

- You may freely distribute the URL identifying the publication in the public portal

If you believe that this document breaches copyright please contact us providing details, and we will remove access to the work immediately and investigate your claim 
See discussions, stats, and author profiles for this publication at: https://www.researchgate.net/publication/335433848

\section{Wind Turbine Wakes in Directionally Varying Wind Shears}

Chapter · August 2019

DOI: 10.1007/978-3-030-22196-6_49

CITATIONS

3 authors, including:

2. Mahdi Abkar

Aarhus University

38 PUBLICATIONS 581 CITATIONS

SEE PROFILE

Some of the authors of this publication are also working on these related projects:

Statkraft Ocean Energy Research Program View project

Project Uncertainty quantification in RANS closures using OpenFOAM View project
READS

111

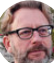

Jens Sørensen

Technical University of Denmark

273 PUBLICATIONS 6,933 CITATIONS

SEE PROFILE 


\title{
Wind turbine wakes in directionally varying wind shears
}

\author{
Mahdi Abkar, Fernando Porté-Agel and Jens N. Sørensen
}

\begin{abstract}
In the atmospheric boundary layer, the Coriolis force associated with the Earth's rotation induces a spanwise wind shear in addition to the wall-normal one leading to a continuous change in wind direction with height. The spanwise wind shear in directionally sheared inflow has a significant impact on the formation and development of wind-turbine wakes. The present work aims to provide an analytical framework for predicting wind-turbine wakes in directionally varying wind shears.
\end{abstract}

\section{Introduction}

In the atmospheric boundary layer, the Coriolis force associated with the Earth's rotation induces a spanwise wind shear in addition to the wall-normal one leading to a continuous change in wind direction with height. The spanwise wind shear in directionally sheared inflow has been shown to have a significant i mpact on the formation and d evelopment of $w$ ind-turbine wakes [1-6]. In particular, it causes a skewed spatial structure in the wake downwind of the turbine and significantly affects the operation of the waked wind turbines [7,8].

In the present work, we aim to provide an analytical framework for wake-flow prediction in directionally varying wind shears. Two sets of wake models are presented. The first approach generalizes the well-known Jensen wake model [9] by assuming a skewed top-hat shape for the wake downwind of the turbine. The second approach extends the Bastankhah and Porté-Agel wake model [10] by considering a skewed Gaussian-like shape for the velocity defect [11]. We use large-eddy simulation (LES) data of the wind-turbine wake in the conventionally neutral regime to evaluate the presented wake models. The rest of the chapter is organized as follows. In Sect. 2, a summary of the LES setup are provided followed by the key simulation results. The analytical wake models are described and assessed in Sect. 3. Finally, a summary is given in Sect. 4.

\footnotetext{
M. Abkar

Department of Engineering, Aarhus University, 8000 Aarhus C, Denmark, e-mail: abkar@eng • au . dk

F. Porté-Agel

Wind Engineering and Renewable Energy Laboratory, École Polytechnique Fédérale de Lausanne, 1015 Lausanne, Switzerland, e-mail: fernando.porte-agel@epfl.ch

J.N. Sørensen

Department of Wind Energy, Technical University of Denmark, 2800 Kgs. Lyngby, Denmark, e-mail: jnso@dtu . dk
} 


\section{Large-Eddy Simulation}

The LES code used here solves the filtered mass conservation and momentum equations and the filtered heat equation. The governing equations include buoyancy and the Coriolis effects. The turbine effect are accounted via the standard actuator-disk approach, and the scale-dependent dynamic approach with the Lagrangian averaging scheme is utilized for the subgrid-scale modeling. The reader can refer to [12-16] for a detailed description of the numerical code.

The inflow condition is generated by simulating a conventionally neutral boundary layer (i.e., a neutrally stratified boundary layer capped by a stably stratified free atmosphere [17]) over a flat terrain. Note that, as shown in previous studies [18-20], the free-atmosphere stratification and the capping inversion significantly affect the structure of the boundary layer and, consequently, the development of wake flow behind wind turbines. The boundary layer is driven with a $8 \mathrm{~m} / \mathrm{s} \mathrm{uniform}$ geostrophic wind. The Coriolis parameter is set to $1.39 \times 10^{-4} \mathrm{rad} / \mathrm{s}$, the potential laps rate in the free atmosphere is $10 \mathrm{~K} / \mathrm{km}$, and the aerodynamic surface roughness is $0.1 \mathrm{~m}$. A horizontal-axis wind turbine with a hub height $\left(z_{h}\right)$ of $70 \mathrm{~m}$, a rotor diameter $(D)$ of $80 \mathrm{~m}$ and a thrust coefficient of 0.75 , is immersed in the flow. The domain is $24 D \times 12 D \times 5.9375 D$ in the streamwise $(x)$, spanwise $(y)$, and wall-normal ( $z$ ) directions, respectively, and it is divided uniformly into $192 \times 96 \times 96$ computational nodes. The wall shear stress is specified according to the Monin-Obukhov similarity theory [21], and the wall heat flux is set to zero. The mean wind speed is forced to be aligned with the turbine axes using a wind-direction controller proposed in [22]. The total simulation time is 9 hours. The instantaneous turbulent fields during the last hour are used in the wake-flow simulation.

The time-averaged horizontal wind speed and wind direction profiles obtained from the precursor simulation are shown in Fig.1. The inflow has a mean hub-height velocity of $U_{h} \approx 6.3 \mathrm{~m} / \mathrm{s}$ with a total turbulence intensity of about $6.7 \%$. Figure 2 illustrates the two-dimensional field of the mean velocity defect $\left(\Delta U=U_{i n}-U\right)$, normalized by $U_{h}$, at different cross-sectional planes downstream. Here, $U_{i n}$ is the incoming wind in the $x$-direction. In addition to the recovery of the wake with downwind distance, the skewness of the wake, as a result of the spanwise wind shear, can be visually acknowledged in this figure.
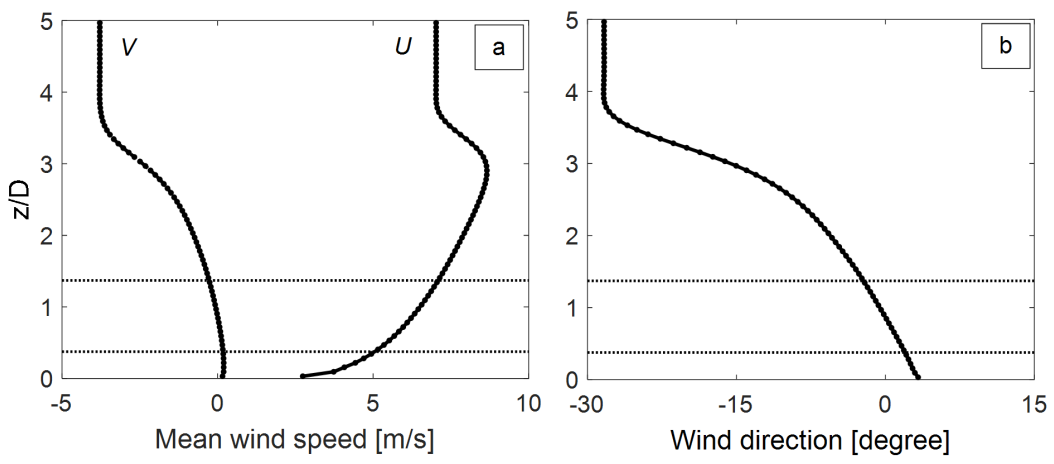

Fig. 1 Time-averaged profiles of the streamwise $(U)$ and spanwise $(V)$ velocity (a) and wind direction (b) in the conventionally neutral regime. The horizontal dotted lines show the rotor extent.

Next, we use the LES data, for the first time, to explore the footprint of the spanwise wind shear on the spatial distribution of the most energetic modes. In this regard, we apply the proper orthogonal decomposition (POD) on the instantaneous velocity deficit field at the $y-z$ plane downwind of the turbine as, $\Delta u^{N}(t, y, z) / U_{h}=\sum_{j=1}^{N} a_{j}(t) \phi_{j}(y, z)$, where the number of snapshots is denoted by 

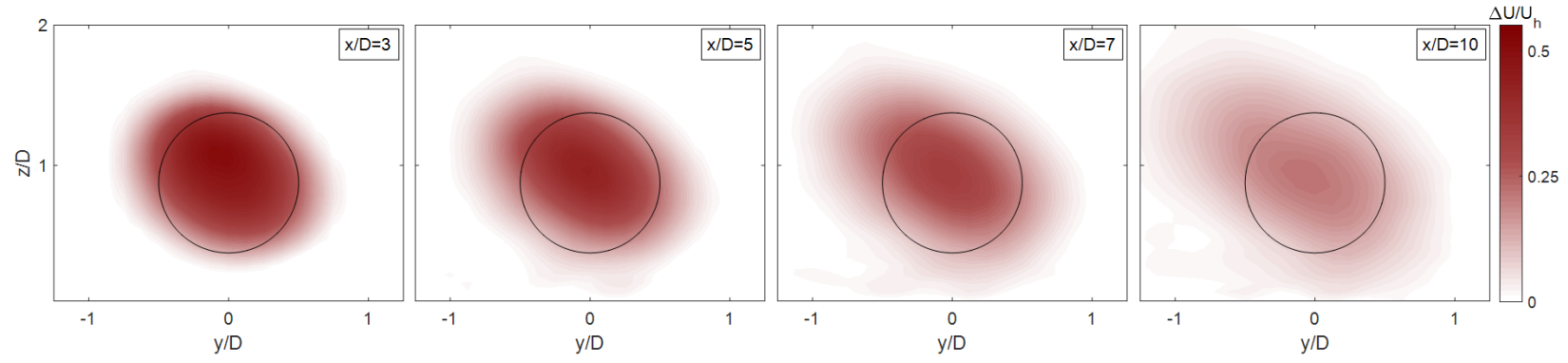

Fig. 2 Normalized velocity defect contours (obtained from the LES) at different cross-sectional planes downstream. The turbine location is shown with a black circle.

$N, \phi_{j}(y, z)$ are the spatial modes, and $a_{j}(t)$ are the time-dependant weighting coefficients. Figure 3 show the spatial modes at $x / D=5$ downwind of the turbine. As can be understood from this figure, the vertical wind veer induces a skewed structure not only on the velocity deficit field, but also on the spatial distribution of the most energetic modes. This is an important finding which can be used in stochastic modeling of wake flow based on POD analysis similar to the one introduced in [23].
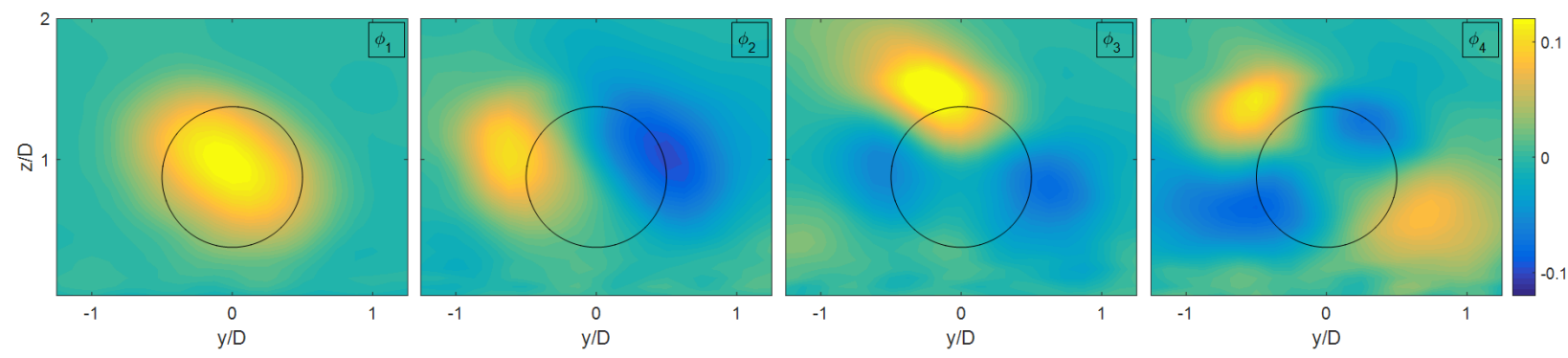

Fig. 3 Time-averaged field and POD modes of the normalized velocity defect at $5 D$ downstream. From left to the right: mode 1 (timeaveraged field), mode 2 , mode 3 and mode 4.

\section{Analytical Wake Models}

Figure 4a illustrates a sketch of the skewed wake in directionally varying wind shears. As discussed in [11], the spanwise wake displacement can be approximated as

$$
\Delta y_{\text {wake }} \approx V_{\text {in }} \Delta t \text { where } \Delta t \approx x / U_{\text {in }} \Rightarrow \Delta y_{\text {wake }} \approx x V_{\text {in }} / U_{\text {in }}=x \tan \left(\alpha_{\text {in }}\right),
$$

where the mean spanwise velocity is denoted by $V_{i n}, \Delta t$ is the airflow travel time from the turbine to the position $x$ downstream, and $\alpha_{i n}$ represents the incoming wind direction. The normalized velocity defect at each $x$ downstream can be described using the skewed version of the previously mentioned top-hat and Gaussian-like wake models $[9,10]$. The skewed top-hat wake model, including the effect of spanwise wind shear, can be written as

$$
\frac{\Delta U}{U_{h}}= \begin{cases}2 a /\left(1+k_{w} x / D\right)^{2} & \text { if }\left[\left(y-x \tan \left(\alpha_{i n}\right)\right)^{2}+\left(z-z_{h}\right)^{2}\right] \leq\left(D / 2+k_{w} x\right)^{2} \\ 0 & \text { for the other locations }\end{cases}
$$


where the expansion rate of the wake is denoted by $k_{w}$, and $a$ represents the axial induction factor which can be estimated using the one-dimensional momentum theory as $a=\left(1-\sqrt{1-c_{t}}\right) / 2$, where $c_{t}$ denotes the thrust coefficient of the turbine. In a similar way, the wake velocity deficit can be represented via the skewed Gaussian-like wake model [11] as

$$
\begin{aligned}
& \frac{\Delta U}{U_{h}}=\frac{\Delta U_{\max }}{U_{h}} \times \exp \left(-\frac{1}{2}\left[\left(\frac{y-x \tan \left(\alpha_{i n}\right)}{k^{*} x+\varepsilon D}\right)^{2}+\left(\frac{z-z_{h}}{k^{*} x+\varepsilon D}\right)^{2}\right]\right), \\
& \frac{\Delta U_{\max }}{U_{h}}=\left(1-\sqrt{1-\frac{c_{t}}{8\left(k^{*} x / D+\varepsilon\right)^{2}}}\right)
\end{aligned}
$$

where $k^{*}$ represents the wake expansion rate, and $\varepsilon=0.2 \sqrt{\left(1+\sqrt{1-c_{t}}\right) /\left(2 \sqrt{1-c_{t}}\right)}$ [10]. Note that the analytical formula for the maximum velocity defect in (3) is based upon the self-similar behaviour of the wake. Hence, close to the turbine, where the full self similarity is not achieved, it might diverge. In order to address this issue, we use the one-dimensional momentum theory and assume that $\Delta U_{\max } / U_{h}$ cannot be greater that $2 a$ and, consequently, its magnitude is set to $2 a$ in the near-wake region [11]. In this study, we adopt $k_{w} \approx 0.04$ and $k^{*} \approx 0.027$ that fit the data best.

Figure $4 \mathrm{~b}$ describes the variations of the maximum velocity defect, normalized by $U_{h}$, obtained from the analytical models and the LES simulation. As can be acknowledged, there is an excellent agreement between the Gaussian-like wake model and LES data, while the top-hat wake model underpredicts the normalized maximum velocity deficit downstream.
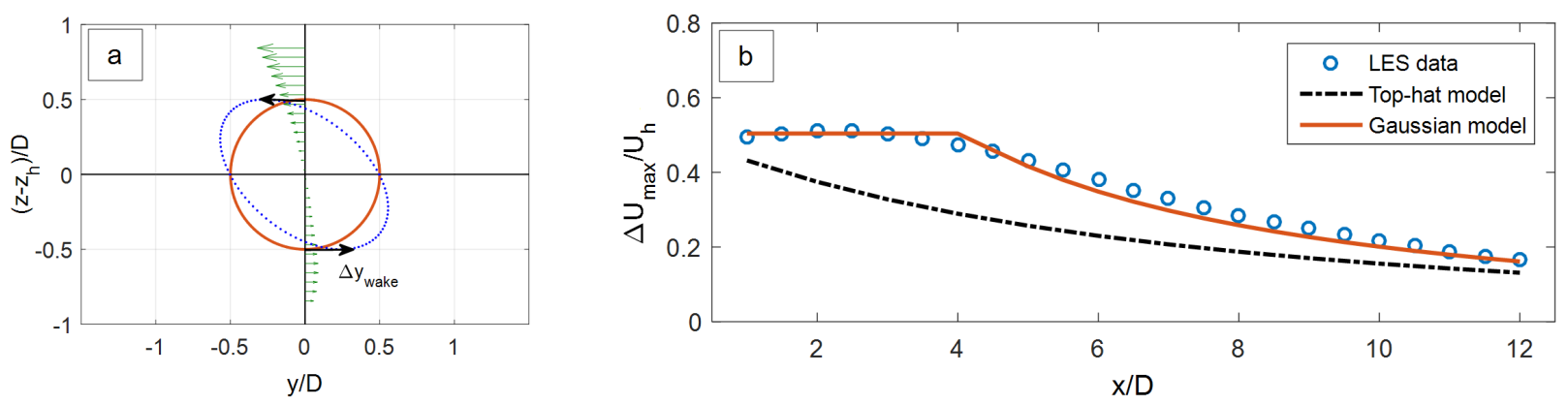

Fig. 4 (a) Sketch of the skewed wake [11]. The green arrows correspond to the spanwise velocity. (b) Maximum velocity defect (normalized by $U_{h}$ ) as a function of the downwind location.

In Fig. 5, the mean fields of the normalized velocity defect predicted by the two wake models at different $y-z$ planes downstream are shown. A more detailed comparison between the analytical models and the LES results are also given in Fig. 6. As can be seen, there is an acceptable agreement between the low-order wake models and the LES results in wake flow prediction. Specifically, both models are able to capture the wake skewing associated with the spanwise wind shear. However, the skewed Gaussian-like wake model provides a more accurate prediction for the spatial distribution of the wake compared to the skewed top-hat model. 

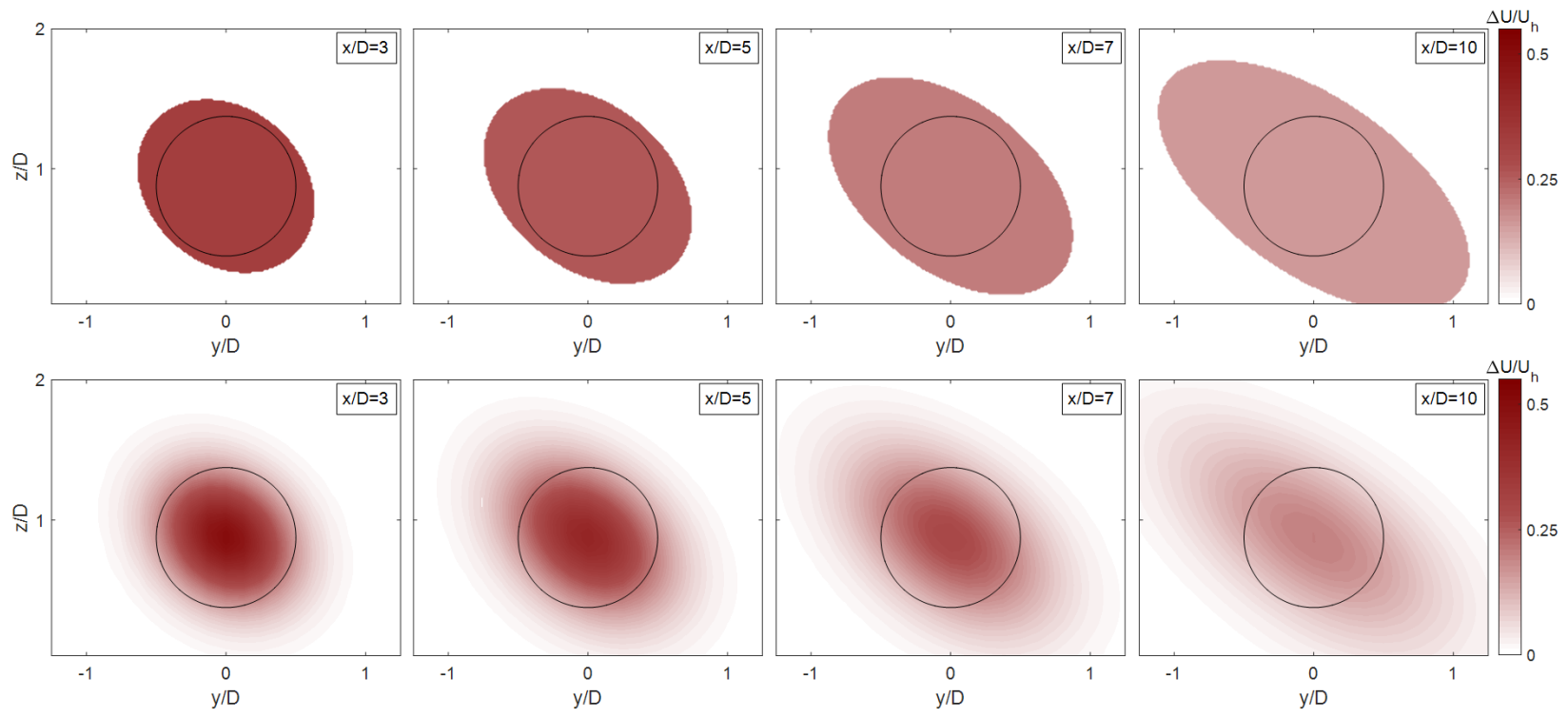

Fig. 5 Same as Fig. 2 but obtained from the skewed top-hat model (top) and the skewed Gaussian-like model (bottom).
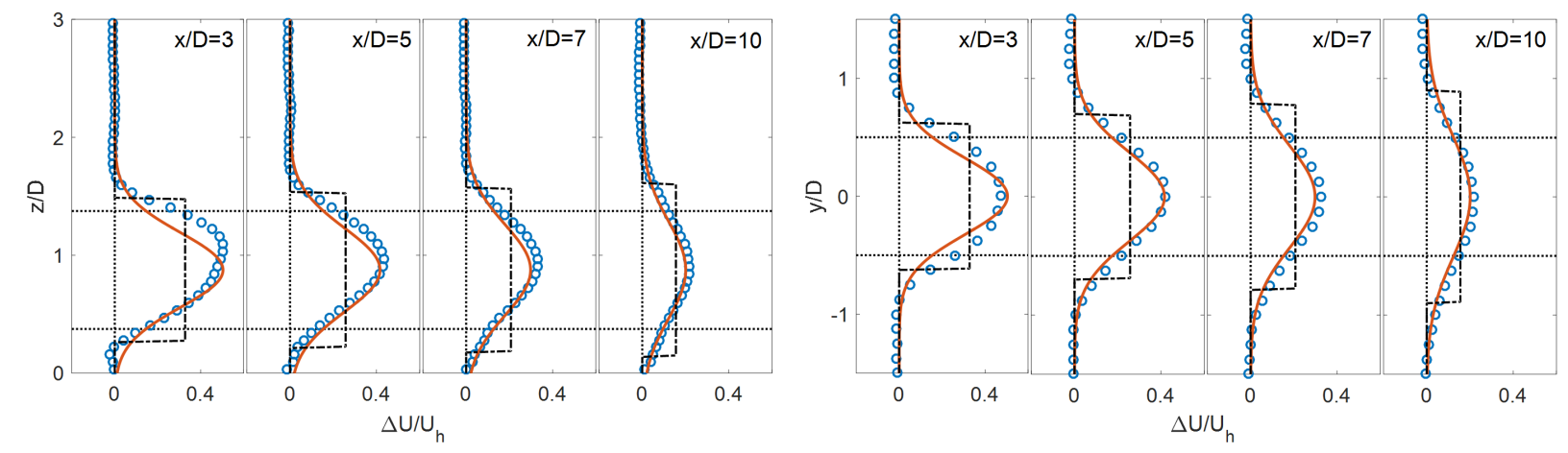

Fig. 6 Velocity defect profiles (normalized by $U_{h}$ ) in the wall-normal (left) and the spanwise (right) directions through the turbine center downstream. LES data (०), the skewed top-hat model (-) ), and the skewed Gaussian-like model (-).

\section{Summary}

We proposed two types of analytical wake models to predict wind-turbine wakes in directionally varying wind shears. While both models satisfy the mass continuity and the momentum conservation, the first model assumes a skewed top-hat distribution and the second approach considers a skewed Gaussian-like shape for the wake velocity defect downstream. In order to evaluate the analytical models, we used the simulation data obtained from the LES of the conventionally neutral boundary layer through a wind turbine. It is shown that both models can capture the wake skewing induced by the spanwise wind shear. However, the skewed Gaussian-like model provides more accurate results in predicting the wake velocity defect (both the magnitude and the spatial distribution) compared to the skewed top-hat counterpart. Note that the proposed models can be implemented in the available numerical codes used for optimization and control purposes under veering inflow conditions [24]. 


\section{References}

1. M. Magnusson, A.S. Smedman, Wind Eng. 18, 139 (1994)

2. H. Lu, F. Porté-Agel, Phys. Fluids 23, 065101 (2011)

3. J. Lundquist, M. Churchfield, S. Lee, A. Clifton, Atmos. Meas. Tech. 8(2), 907 (2015)

4. M. Abkar, F. Porté-Agel, Phys. Rev. Fluids 1, 063701 (2016)

5. M. Bromm, L. Vollmer, M. Kühn, Wind Energy 20(3), 381 (2017)

6. T. Herges, D.C. Maniaci, B.T. Naughton, T. Mikkelsen, M. Sjöholm, J. Phys.: Conf. Ser. 854(1), 012021 (2017)

7. M. Abkar, A. Sharifi, F. Porté-Agel, J. Turbul. 17(4), 420 (2016)

8. M.P. van der Laan, N.N. Sørensen, Wind Energy Sci. 2(1), 285 (2017)

9. N. Jensen, A note on wind turbine interaction. Tech. Rep. Ris-M-2411., Roskilde, Denmark: Roskilde National Laboratory (1983)

10. M. Bastankhah, F. Porté-Agel, Renew. Energy 70, 116 (2014)

11. M. Abkar, J. Sørensen, F. Porté-Agel, Energies 11(7), 1838 (2018)

12. F. Porté-Agel, Y.T. Wu, H. Lu, R.J. Conzemius, J. Wind Eng. Ind. Aerodyn. 99(4), 154 (2011)

13. Y.T. Wu, F. Porté-Agel, Boundary-Layer Meteorol. 146, 181 (2013)

14. M. Abkar, F. Porté-Agel, Phys. Fluids 27(3), 035104 (2015)

15. M. Abkar, F. Porté-Agel, J. Renew. Sustain. Energy 7(1), 013121 (2015)

16. X.I. Yang, M. Abkar, J. Fluid Mech. 842, 354 (2018)

17. S. Zilitinkevich, I. Esau, Boundary-Layer Meteorol. 104, 371 (2002)

18. M. Abkar, F. Porté-Agel, Energies 6, 2338 (2013)

19. M. Abkar, F. Porté-Agel, Renew. Energy 70, 142 (2014)

20. D. Allaerts, J. Meyers, Phys. Fluids 27(6), 065108 (2015)

21. C. Moeng, J. Atmos. Sci. 46, 2311 (1984)

22. A. Sescu, C. Meneveau, Q. J. R. Meteorol. Soc. 140(683), 2017 (2014)

23. D. Bastine, L. Vollmer, M. Wächter, J. Peinke, Energies 11(3), 612 (2018)

24. G. Iungo, C. Santoni-Ortiz, M. Abkar, F. Porté-Agel, S. Leonardi, J. Phys.: Conf. Ser. 625(1), 012009 (2015) 